\title{
Los proverbios árabes clásicos más usados
}

\section{The most commonly used classical Arabic proverbs}

\author{
Ahmed-Salem Ould MOHAMED BABA \\ Universidad Complutense de Madrid \\ aouldmoh@filol.ucm.es
}

Recibido: febrero 2012

Aceptado: abril 2012

\section{RESUMEN}

Este trabajo contiene una colección de los proverbios árabes clásicos más usados tanto en el discurso oral como en el escrito. A pesar de la antigüedad de algunos de ellos, se siguen usando, lo que demuestra la vitalidad de esta clase de enunciados.

Palabras claves: Proverbios árabes antiguos, Paremiología árabe, Paremiología comparada, Lexicografía árabe.

\section{ABSTRACT}

This article examines a collection of the most commonly used classical Arabic proverbs both in written and oral discourse. In spite of their remote origin, some of them are still alive in Standard Arabic, what demonstrates the vitality of this kind of sapiential expressions.

Keywords: Old Arabic proverbs, Arabic paremiology, Comparated paremiology, Arabic lexicography.

SUMARIO: 1. Introducción, 2. Selección de proverbios. 


\section{INTRODUCCIÓN}

La presente selección de proverbios y fraseologismos árabes traducidos y anotados la forman proverbios pertenecientes a las distintas colecciones que se han conservado en el mundo árabe y abarca un periodo que va desde el siglo VI hasta el siglo XIII (desde la época preislámica, pasando por la época de los Califas, la época de los Omeyas hasta llegar a la época Abbasí).

Se sabe que los árabes usaban un gran número de proverbios en la época preislámica llamada al-ğăhiliyya ${ }^{1}$ los cuales fueron transmitidos oralmente hasta que se recogieron a partir del siglo VIII. Los proverbios de aquella época reflejan el pensamiento, la sabiduría ${ }^{2}$ y el modo de vida de los árabes que eran, en su mayoría, nómadas. Más tarde, la transición de una situación de politeísmo a una de monoteísmo con el Islam significó el cambio de muchos enunciados paremiológicos antiguos para adaptarse a la nueva realidad.

En la época Omeya, se inició el interés por la recopilación de proverbios y se recogieron anécdotas, fábulas e historietas que contenían o explicaban algunos proverbios.

La larga época Abbasí (750-1250), fue el periodo de mayor esplendor cultural del mundo árabe e islámico, marcado por una labor extraordinaria en todos los campos del saber, incluida la paremiología, que aparece como una fuente importante para los estudios lingüísticos y lexicográficos.

La presente colección de proverbios, a pesar de pertenecer a diferentes épocas, se sigue usando en los textos escritos (artículos de prensa, ensayos, informes, cartas, manuales de temática diversa, etc.) y en el discurso oral de los árabes que dominan el árabe clásico, de manera que es frecuente oírlos en los parlamentos, en los diferentes medios de comunicación, en las conferencias, etc.

Dado el carácter especial que tienen los proverbios y que dificulta su traducción, hemos procurado dar los equivalentes castellanos de la mayoría de los proverbios seleccionados.

\section{SELECCIÓN DE PROVERBIOS}

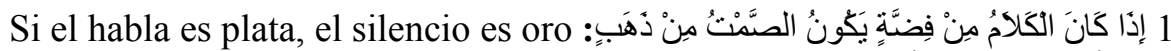
2 Si vives con una gente, ordeña en su ordeñadero 2

${ }^{1}$ La găhiliyya es la denominación que recibe el largo periodo histórico anterior al advenimiento del Islam, étapa histórica marcada por una sociedad tribal con un modo de vida nómada, aunque había unos pocos centros urbanos a los que se acudía para las ferias y para el culto politeísta. Para más detalles acerca de este periodo, véase Enciclopedia del Islam (EI), págs. 393-394, sv DJāhiliyya.

${ }^{2}$ De la misma manera que los griegos crearon la filosofía, a partir de la reflexión sobre lo que les rodeaba, el pueblo árabe legó a sus generaciones estos textos breves que resumen sus experiencias, sus observaciones, su conocimiento de la naturaleza y del hombre.

${ }^{3}$ Equivale a "Donde fueres, haz lo que vieres", v. Varios Autores, 1001 refranes españoles con sus correspondencias en alemán, árabe, francés, inglés, italiano, polaco, provenzal y ruso, Madrid 2001, p.116. 
3 Cuando sople tu viento, aprovéchalo: 3

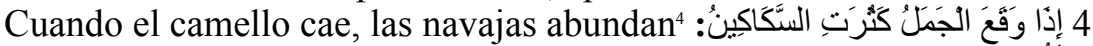
5

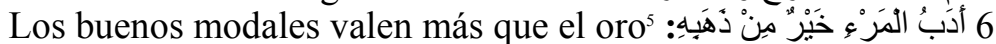

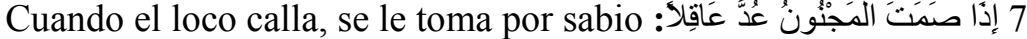
Haz el bien y no mires a quién 8

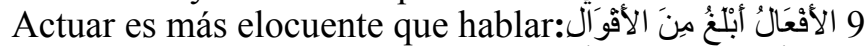
10

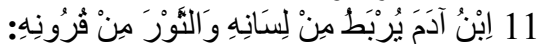

Al ser humano se le pilla por su lengua y al toro por sus cuernos

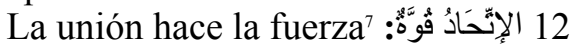

13 14

Guárdate una vez de tu enemigo y mil veces de tu amigo

15 آخرُِ الدَّوَائ الكَيُ:

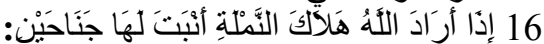

Cuando Dios quiere que la hormiga perezca, le pone alas

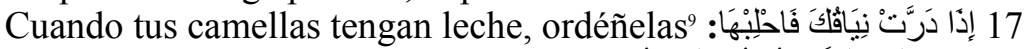

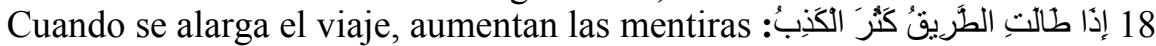

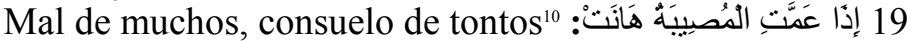

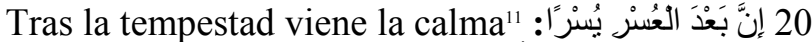

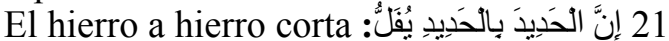

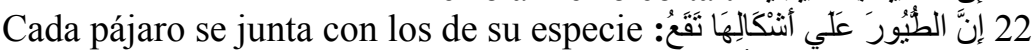

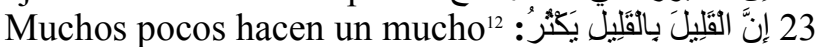

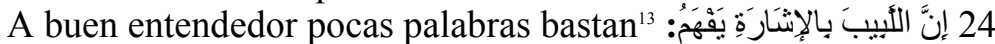

25

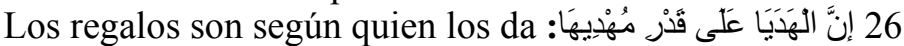

27

28

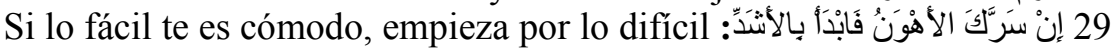

${ }^{4}$ Equivale a "Al perro flaco, todo son pulgas", v. Martínez Kleiser, Luis, Refranero general ideológico español, Madrid, 1989, pág. 185 (refr. $n^{\circ}$ 16.795).

${ }^{5}$ Lit.: "La educación de una persona es mejor que sus bienes".

${ }^{6}$ Lit.: "Haz el bien y tíralo al mar".

${ }^{7}$ Lit.: "La unidad es fuerza".

${ }^{8}$ Equivale a: "Por interés, te quiero Andrés".

${ }^{9}$ Hay que aprovechar las oportunidades cuando surgen.

${ }^{10}$ Lit.: "Si se generaliza la desgracia, se vuelve llevadera". Cf. "mal de muchos, consuelo de tontos".

${ }^{11}$ Lit.: "Tras la dificultad viene la facilidad".

${ }^{12}$ Lit.: "Lo poco con otro poco hacen un mucho".

${ }^{13}$ Lit.: "El sagaz entiende con una insinuación".

${ }^{14}$ Equivale a: "De tal palo, tal astilla". 
30 الأمُورُ بعَوَاقِبهَها: Los hechos se juzgan por cómo acaban 31

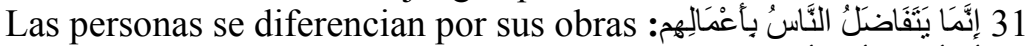
32

Yo soy príncipe y tú eres príncipe ¿Quién guiará los asnos?

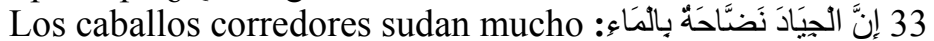

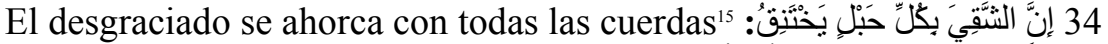

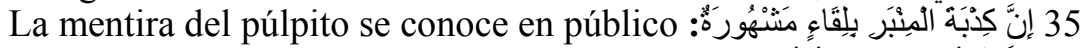

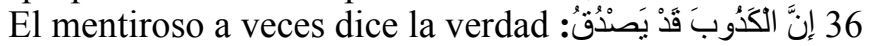

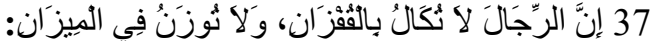

Los hombres no se miden en cahíces, ni se pesan con básculas

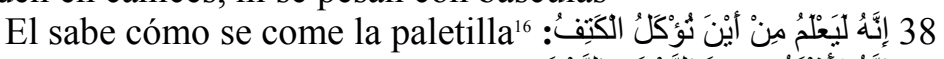

39 Tan iguales como dos dátiles 39

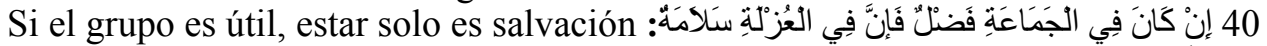

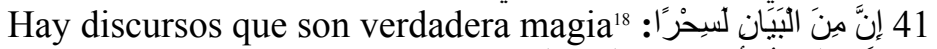

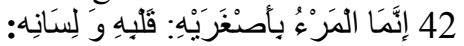

La persona se mide por sus dos más pequeñas partes: su corazón y su lengua

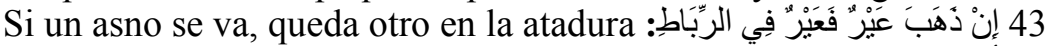

Más irritable que el hijastro de un rey 44

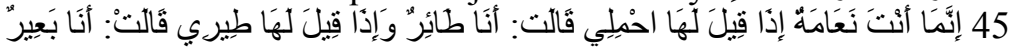

Eres como el avestruz, si se le dice, lleva bultos, contesta, soy un ave y cuando se le dice vuela, contesta, soy un camello

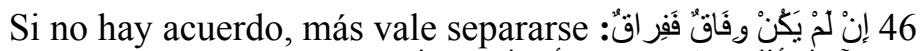

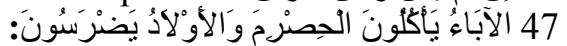

Los padres comen uvas agraces y los hijos tienen dentera

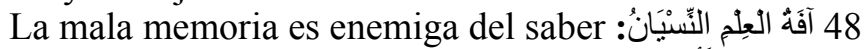

49 Lejos de mí el consejo precipitado:

50

51

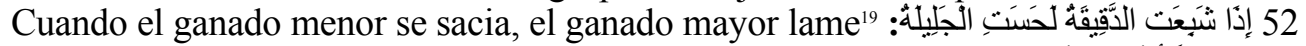

Cuando tu hermano se vuelve poderoso, humíllate 53

54 Si no es lo que tú quieres, quiere lo que es 53 Más avaro que un perro ante un hueso (descarnado) 55

56 أَجْوَدُ مِنْ حَانِتِ

${ }^{15}$ Equivale a: "A perro flaco, todo se le vuelven pulgas".

${ }^{16}$ Significa saber comportarse, tener educación y buenos modales.

${ }^{17}$ Equivale a: "Como dos gotas de agua".

${ }^{18}$ Al-Maydani, A. Magma 'al-amtal. (ed.) Zarzur, N. H. Beyrut 1987, 2 vols., (citado en adelante como Al-Maydān̄̄), prov. $\left.n^{\circ} 1\right)$; La frase es atribuida al Profeta Muhammad.

${ }^{19}$ Al-Maydānī I, 102 (prov.n ${ }^{\circ} 331$ ), según él, hace referencia al pobre que trabaja para el rico.

${ }^{20}$ Al-Maydānī I, 35 (prov.n ${ }^{\circ} 63$ ).

أبخل من كلب Con la variante

${ }^{22}$ Personaje preislámico conocido por su generosidad legendaria en toda Arabia. 
Más necio que el pastor de ochenta ovejas 57

58 أخَذَ القُوسنَ بَار يهَا: 58

Más tonto que Habannaqa 59

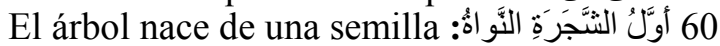
61

Más firme que una roca 62

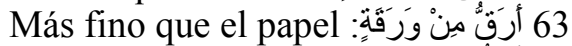

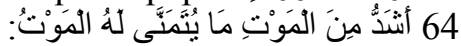

Más dura que la propia muerte es la razón por la que se desea

Más maligno que una serpiente 65

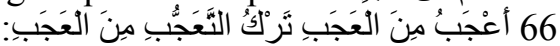

Dejar de maravillarse de lo maravilloso es más maravilloso que lo que te maravilla

Más traidor que un chacal 67

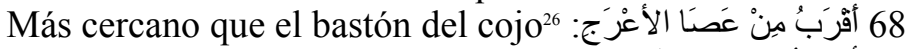

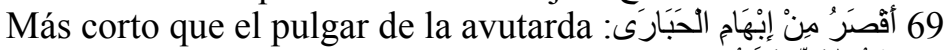

El hijo de la oca es nadador 70

Se tocaron las dos anillas de la barriguera 71

Más suave que la seda 72

Más cortante que la espada 73

Más seguro que las palomas de La Meca29 74

75 آحَنُ مِنْ غِزْْلَن مَكَّة: Más seguro que las gacelas de La Meca

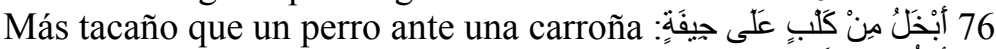

Más fiel que una gata: 77

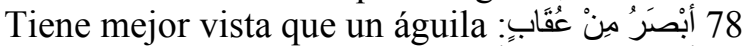

Más inaccesible que los huevos del buitre 79

Más atrevido que el león 80

Haz que tu perro pase hambre y te seguirá 81

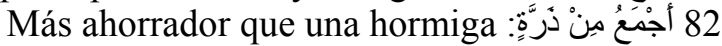

${ }^{23} \mathrm{~V}$. Blachère, R. "Contribution à l'étude de la littérature proverbiale des arabes à l'époque archaïque", Arabica 1, pp. 53-83. En la pág. 80, traduce este proverbio así: "plus sot que pasteur de quatre-vingts moutons".Además se plantea, como es lógico, la razón de la necedad del pastor y, tras recoger las diferentes versiones del proverbio, considera que debería tratarse de un pastor que pretendía mantener juntas ochenta ovejas: أحمق من طالب ضأن ثمانين.

أعُطي القوس باريها Con la variante

${ }^{25}$ V. Al-Maydānī I, 281 (prov. $n^{\circ} 1168$ ) que indica que el personaje Habannaqa era Yazīd b.Tarwān de la tribu Banū Qays que era bien conocido por su necedad. Blachère (1954:77) cita este proverbio.

${ }^{26}$ En Al-Maydānī II, 154 viene enunciado: أقرب من حبل الوريد، و من عصا الأعرج: "Más cercano que la yugular y que el bastón del cojo".

${ }^{27}$ Significado: "El asunto se puso negro".

السَّرقَة من جيد الحرير او أبيضه : o sea, "la mejor calidad de la seda, o la seda blanca”, según Hārūn (1968:I,169).

${ }^{29}$ El Islam prohibe cazar en los lugares santos, como son la Meca y Medina.

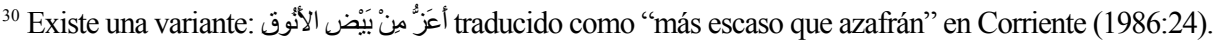


83

Más hambriento que la perra de Hawmal 84

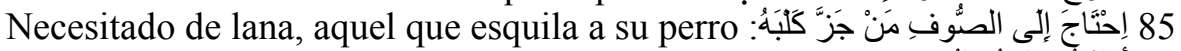

Más precavido que un pájaro: 86

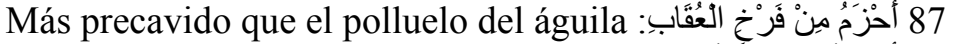

Más hermoso que un pavo real 88

Más vivo que un lagarto: 89

90 91

92

Más engañoso que un lagarto: 93 94 95

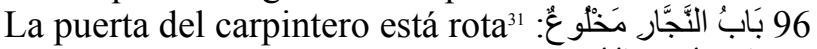

97

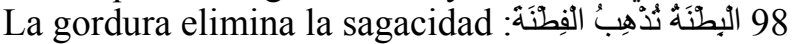

La lejanía es desdén 99

100 101 102

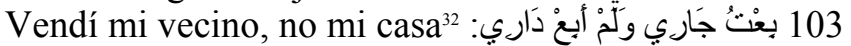

En todos los valles están los Banū Sac di 104

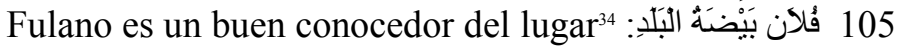

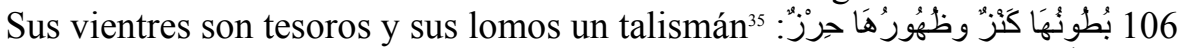

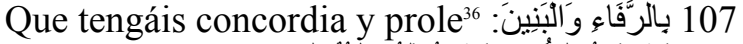

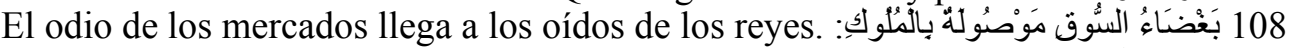

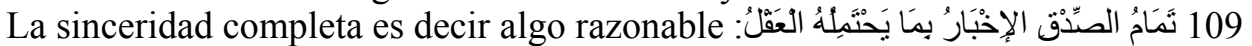

Debajo de la nata está la leche pura 110

La sabiduría completa es la humildad 111 112

Los ves jóvenes (grandes y sanos) como las palmeras, pero no sabes qué enfermedad tienen ${ }^{37}$

${ }^{31}$ Equivale a: "En casa del herrero, cuchillo de palo".

${ }^{32}$ Alude a quien se ve obligado a cambiar de casa por tener un mal vecino.

${ }^{33}$ V. Al-Maydānī I, 149 (prov. $\mathrm{n}^{\circ}$ 526). Banū $\mathrm{Sa}^{\mathrm{c}} \mathrm{d}$ es una tribu conocida de Arabia; el proverbio lo atribuyen a un miembro de esta tribu que la dejó por desavenencias con ella y, tras estar algún tiempo con otra, empezó a tener los mismos problemas, como consecuencia de esto dijo esta frase. Equivale a بكلِّ وَّدِ

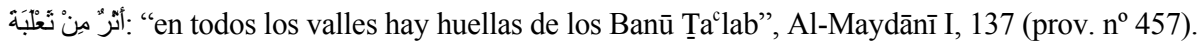

${ }^{34}$ Lit.: Fulano es el huevo del lugar.

${ }^{35}$ Es una referencia a las yeguas; se atribuye al profeta Muḥammad.

${ }^{36}$ Fórmula que se dice a los recién casados. 
Es mejor oír hablar de al-Mu'aydī a que lo veas 113

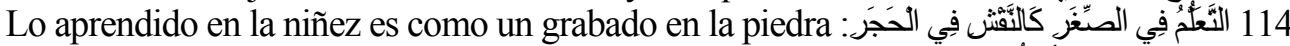

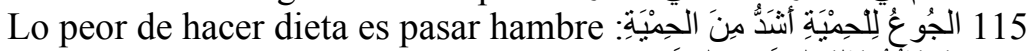

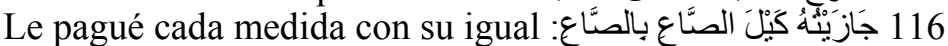

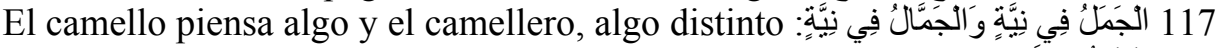
La recompensa de Sinimmāri 118

Trajo de todo, lo que pía y lo que calla 119

120

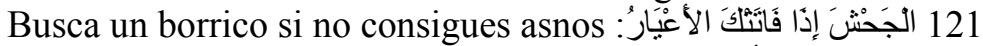

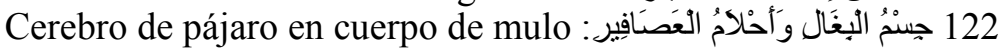

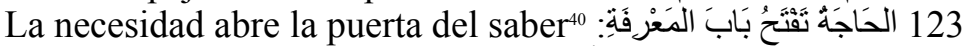

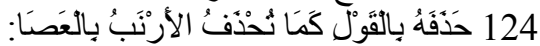

Lo eliminó de sus palabras como desaparece el conejo con la varita

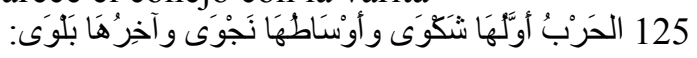

El inicio de la guerra es una queja; su transcurso es desconocido, y su final, una desgracia.

126

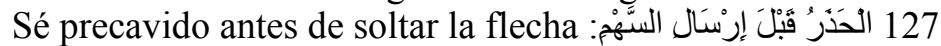

128

129

Cuando el cielo caiga sobre la tierrat1 130 131

132

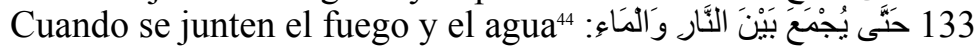

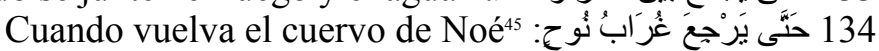

135

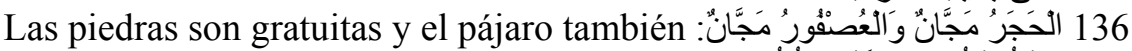

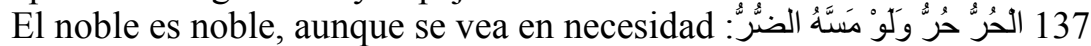

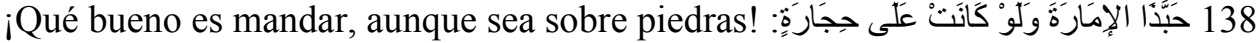

${ }^{37}$ Figura con la misma redacción en Al-Maydānī I, 186 (prov. $n^{\circ}$ 685); de la anécdota y la larga nota explicativa, se entiende que los aspectos son engañosos y que pueden verse personas muy grandes y aparentemente sanas y averiguar luego que están enfermas.

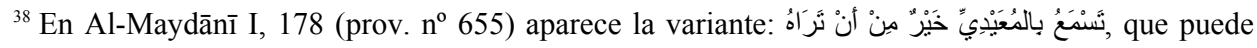
traducirse de la misma forma.

${ }^{39} \mathrm{Se}$ trata de un arquitecto que construyó un palacio de una belleza inigualable cuyo dueño lo arrojó desde la torre más alta para que no volviera a construir en su vida otro igual.

${ }^{40} \mathrm{O}$ sea, la necesidad es gran maestra, v. Martínez Kleiser pág. 516, refrán no 45.169.

${ }^{41}$ Forma parte de una serie de expresiones que significan "nunca".

${ }^{42}$ Expresiones que significan "nunca".

${ }^{43}$ Expresiones que significan "nunca".

${ }^{44}$ Expresiones que significan "nunca".

${ }^{45}$ Expresiones que significan "nunca".

${ }^{46}$ Expresiones que significan "nunca". 
139 الحُبُ أعْمَى: 140

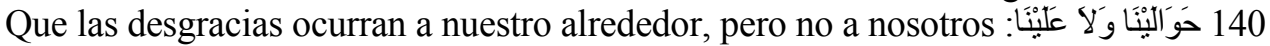

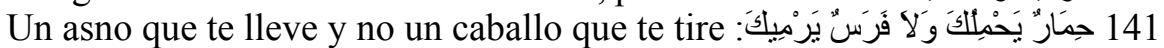

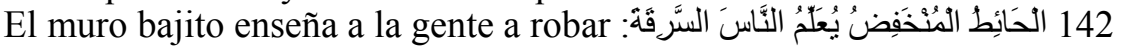

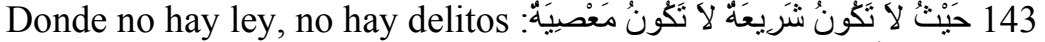

144

145

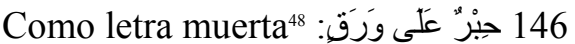

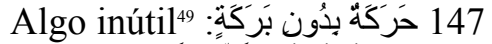

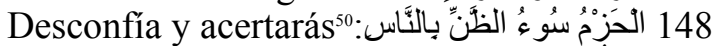

149 حُبُُّ الوَطَنْ مِنَ الإيمَان: El amor a la patria es un acto de piedad

150

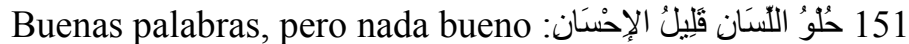

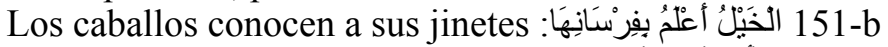

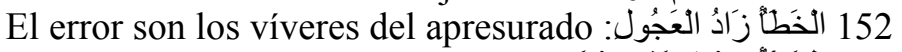

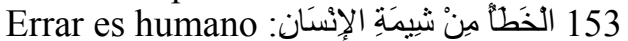

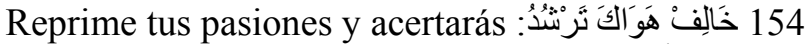

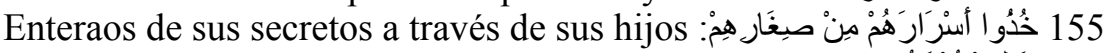

156

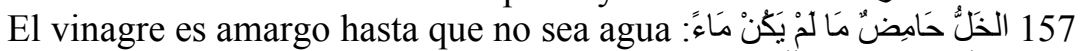

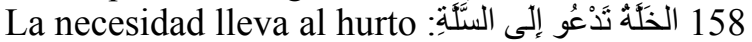

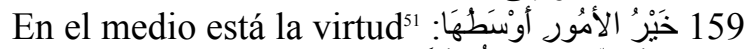

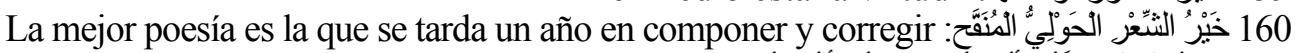
161

La mejor riqueza es un troquel afilado y un caballo obediente

162

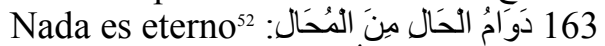

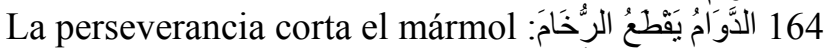

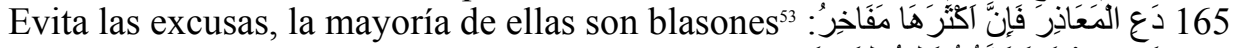

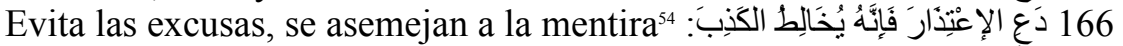

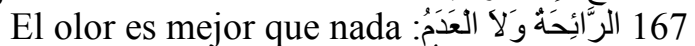

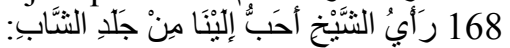

Más querido que la firmeza del joven, es el consejo del anciano

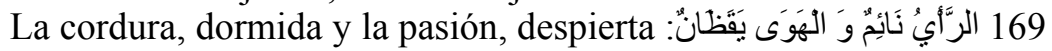

\footnotetext{
${ }^{47}$ Basora es una ciudad conocida por sus inigualables dátiles.

${ }^{48}$ Lit.: "Tinta sobre papel".

${ }^{49}$ Lit.: "Movimiento sin bendición".

${ }^{50}$ Lit.: "La prudencia consiste en desconfiar de la gente" y equivale en castellano a: "Piensa mal y acertarás".

${ }^{51}$ Lit.: "Lo mejor del asunto está en el medio".

${ }^{52}$ Lit.: "Ninguna situación es eterna".

${ }^{53}$ Está redactado de forma diferente en Al-Maydānī II, 350 (prov. no 3995): المعاذر مكاذب.

${ }^{54}$ En Al-Maydān̄̄ II, 350 (prov. no 3996): المعانر قد يثوبها الكنب “Las excusas a veces se mezclan con la mentira”.
} 
A veces el enojo lleva a la ruina 170

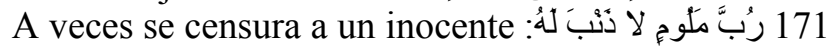

A veces una comida impide las comidas posteriores 172

Agradar a todos es meta inalcanzable 173

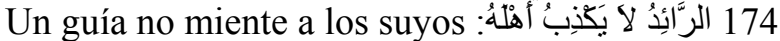

Me contagió su enfermedad y se fue 175

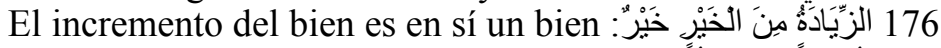

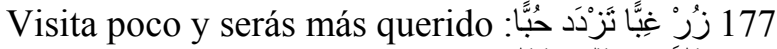

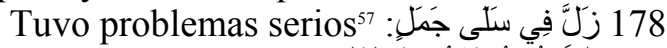

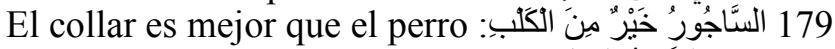

La espada se adelantó al reproche 180

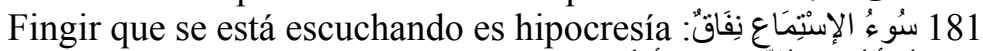

Hay que preguntar a los del oficio por su oficio 182

183

184

Afortunado es aquel que escarmienta con lo que le ocurre a los demás

Engorda a tu perro y te comerá 185

El poder se alcanza en la juventud 186

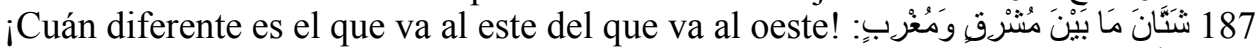

188

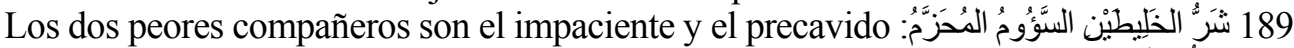

190

191

El martirio es la muerte más honorable 192

193

194

195

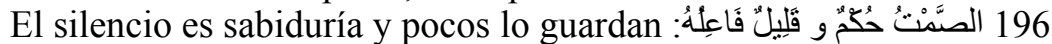

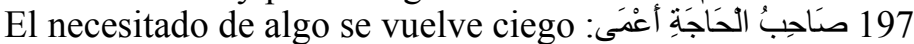

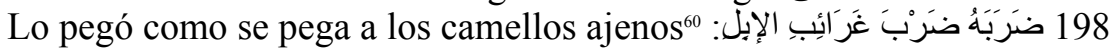

199

200

201

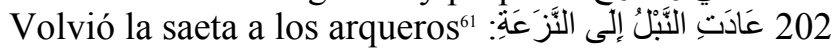

\footnotetext{
${ }^{55}$ Hace referencia a la comida que puede ser causa de muerte.

${ }^{56}$ En Al-Maydānī no 1584 aparece con una variante غَايَّة لا نُدركَ

${ }^{57}$ Lit.: "resbaló en el amnios de un camello".

${ }^{58}$ Eso es, "a buenas horas mangas verdes".

${ }^{59}$ Quiere decir que en la juventud se puede conseguir todo. Lit.: "El poder se consigue teniendo el pelo todavía negro".

${ }^{60} \mathrm{O}$ sea, fuertemente y sin piedad.

عاد السهم إلى النزعة Existe otra expresión similar: "La cosa ha vuelto a sus dueños”, v. Corriente (1986:754).
} 


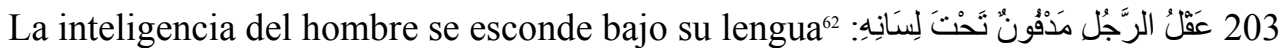

204

205

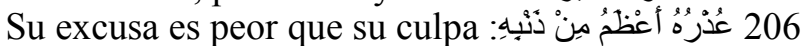

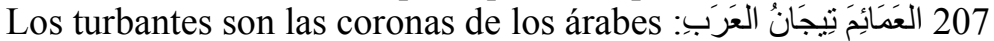

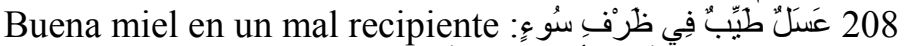

209

210

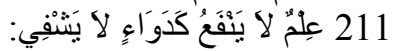

Un conocimiento que no es útil es como un medicamento que no cura

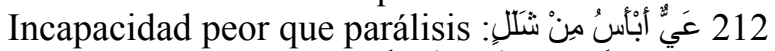

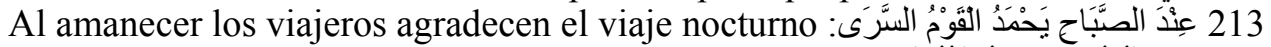

214

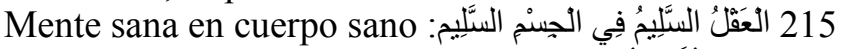

216

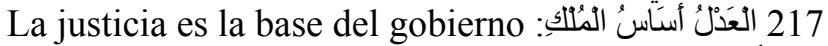

218

219

220

221

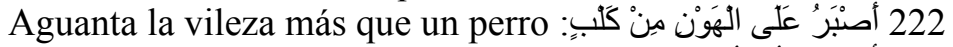

223

Más transparente que el ojo del gallo 224

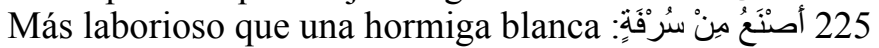

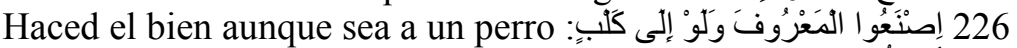

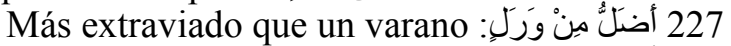

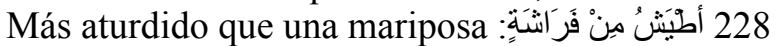

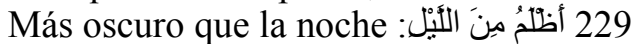

230

231

232 أعَدَى مينَ الجَرَب: 233

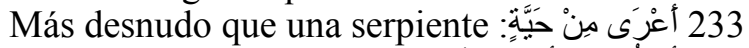

234

235

236 أعََّا مِنْ بَاقِلِ: 235

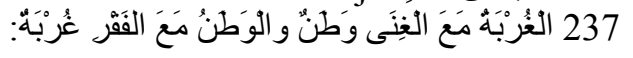

${ }^{62} \mathrm{La}$ forma de hablar es reflejo de la inteligencia.

${ }^{63}$ Para la primera parte del proverbio, v. Al-Maydānī I, 44 (prov. $n^{\circ} 32$ ). Equivale a: "De tal palo, tal astilla".

${ }^{64}$ Lit.: "Volvió con las zapatillas de Ḥunayn".

${ }^{65}$ Idéntico en el refranero de Azzajjāllī, refrán no 517, v.Ould Mohamed Baba (1999:75).

se puede traducir por la expresión “pedir leche de pájaro”. 
El exilio con riqueza es una patria y la patria con pobreza es un exilio

238 فازَ بالكألَات الجَسُورُ: 239

239

240

241

242

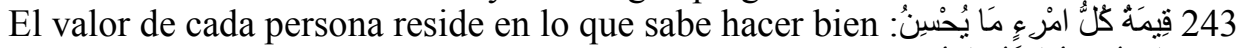

244

245

246

Más corto que el pulgar del lagarto: 247

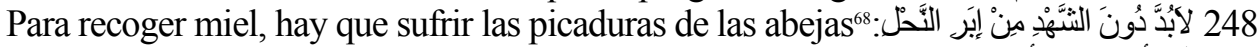

249

250

251

252

253

254

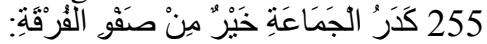

La molestia del grupo es mejor que la serenidad de la ruptura

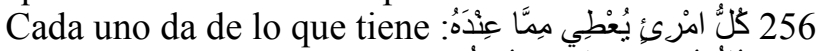

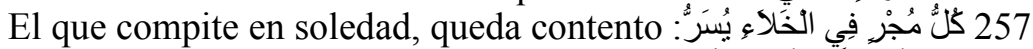

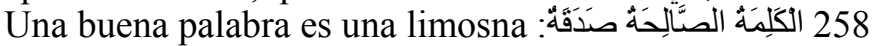

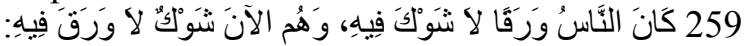

Las personas eran hojas sin espinas, y ahora son espinas sin hojas

260

261

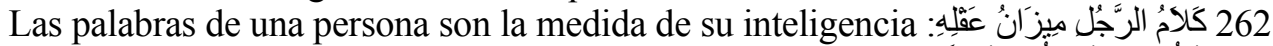

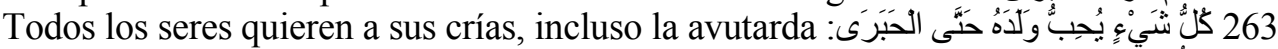

Cada pájaro caza a su medida: 264

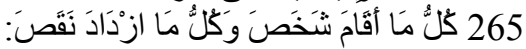

Todo el que permanece acaba viajando y todo lo que aumenta mengua

266 الكِلابِ عَلى اليَقَر : Azuza a los perros para echar a las vacas

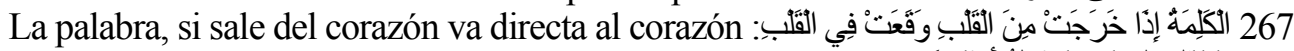

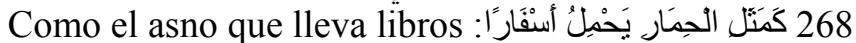

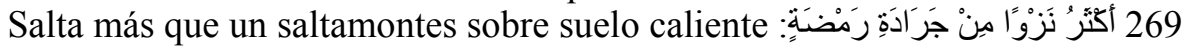

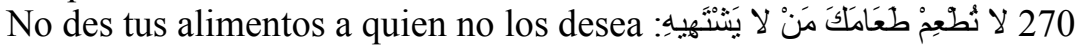

\footnotetext{
${ }^{67}$ Estos dos elementos son la mejor vía hacia el saber según los sabios árabes.

${ }^{68}$ Equivale a: "El que algo quiere, algo le cuesta".

${ }^{69}$ Lit.: "Tiene excusa quien advierte".

${ }^{70}$ Nombre de una ciudad de Arabia, conocida por la calidad y la cantidad de sus dátiles. V. AlMaydānī II, 182 (n 3080).
} 


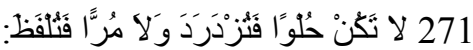

No seas dulce, pues serás comido, ni amargo, pues serás escupido

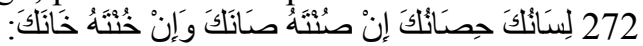

Tu lengua es tu caballo, si la guardas te guarda y si la traicionas te traiciona

273 لا رَابيَ لِمَنْ لانُطُعَ: De nada vale la opinión de quien no es obedecido

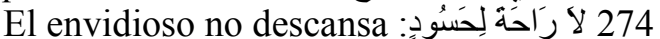

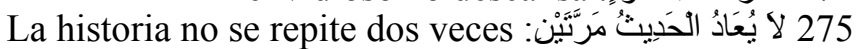

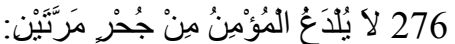

El creyente no acepta ser mordido dos veces desde el mismo nido de serpientes ${ }^{71}$

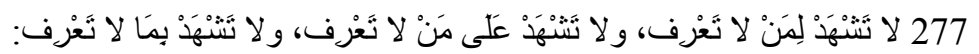

No seas testigo de un desconocido, ni testimonies contra un desconocido, ni des un falso testimonio

Todo tiene una cumbre y la de la buena acción es su rapidez

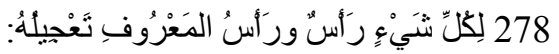

279 لا نَاقَة لِِي فِي هَذَا وَلَا جَمَلَ: 280

280

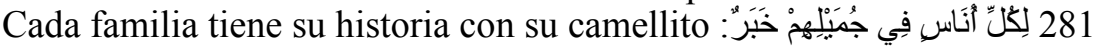

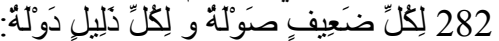

Cualquier débil puede tener fuerza y cualquier vil puede tener poder

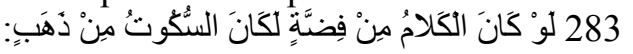

Si hablar fuera de plata, el silencio sería de oro

284

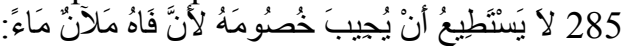

No puede contestar a sus adversarios porque tiene la boca llena de agua

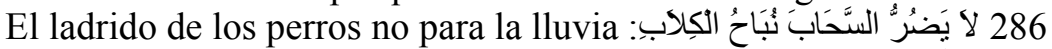

287 لِكلِِّ غَدِ طَعَامُ: 286

288

289

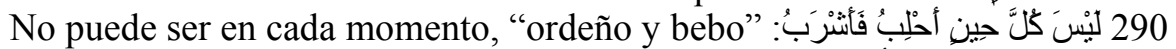

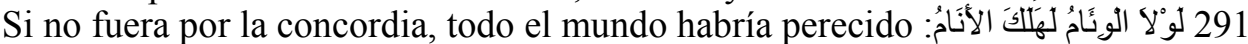

292 مَا مَضَنَى فَاتَ: 293

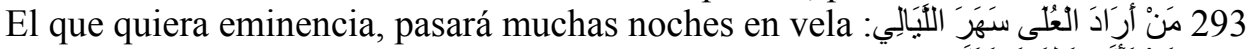

294

295

El que siembra, recoge 296

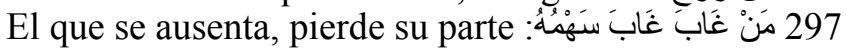

\footnotetext{
${ }^{71}$ No tropieza dos veces con la misma piedra.

${ }^{72}$ Lit.: "No tengo camella ni camello en esto".

${ }^{73}$ Equivale a: "Dios proveerá".

${ }^{74}$ Equivalente castellano: "Sobre gustos, no hay nada escrito".
} 


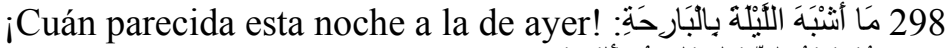
299

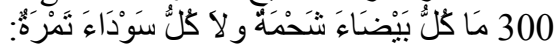
No toda cosa blanca es grasa ni toda cosa negra es dátil

¿Qué difícil es el destete de los mayores! 301 Mientras un océano moje una lana 302

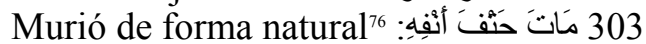

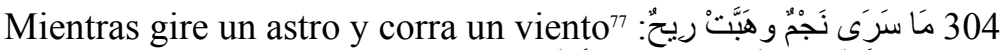

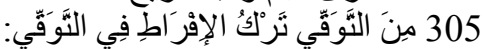

Es parte de las precauciones el evitar el exceso de precaución

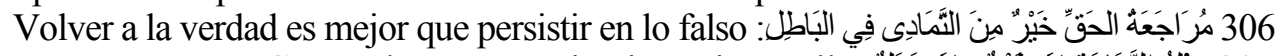

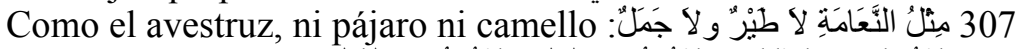

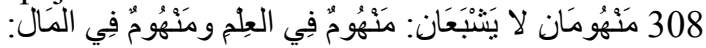

Dos ávidos no se sacian; el ávido de saber y el ávido de riqueza.

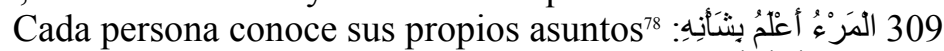

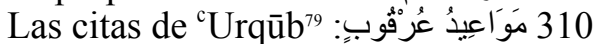

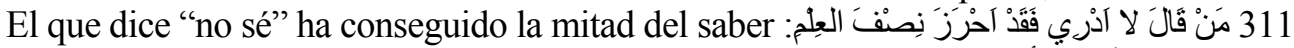

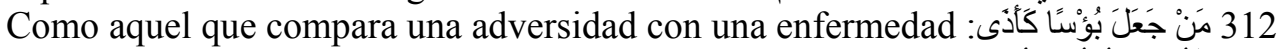

Acata lo que te dice aquél al que pides consejo 313

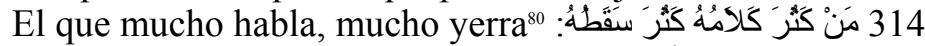

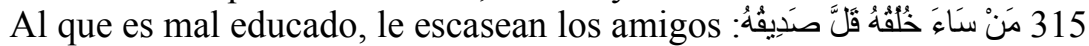

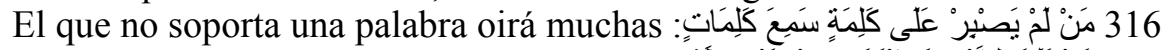

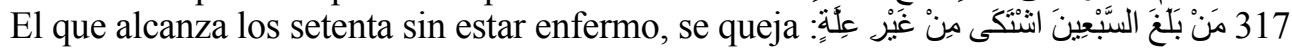

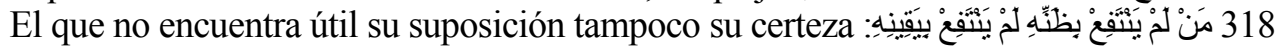

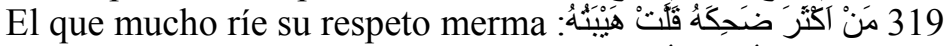

El que perdona será perdonado 320

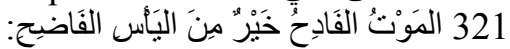

La muerte calamitosa es mejor que la desesperación deshonrosa

322

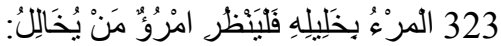

Se deben escoger las amistades pues las personas se miden por ellas

324 مَنْ حَفَرَ مُغَوَّاةَ وقَعَعَ فِيَها:

${ }^{75}$ En el sentido de eternidad.

${ }^{76} \mathrm{~V}$. Blachère, R. "Contribution à l'étude de la littérature proverbiale des arabes à l'époque archaïque", Arabica 1, pág. 58 lo traduce así: "Il est mort de mort naturelle”. Idéntico en Al-Maydān̄̄ II, 314 (prov. $n^{\circ} 3770$ ).

${ }^{77}$ Para siempre.

${ }^{78}$ V. Pellat, Ch. "Sur la formation de quelques expressions proverbiales en arabe", Arabica 23, pág. 9 relata la anécdota que dio origen a esta expresión y la traduce: "Forcé ton frère, pas héros". V. También Al-Maydānī II, 374 (prov. nº 4117).

${ }^{79}$ Se refiere a las falsas citas.

${ }^{80}$ Idéntico en Kleisser, pág. 333, refr. no 29.357. 


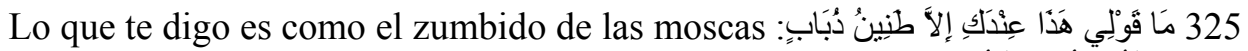

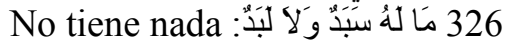

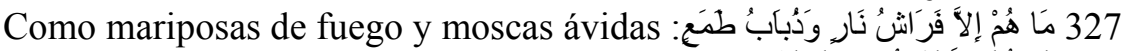

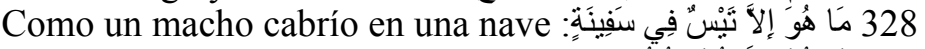

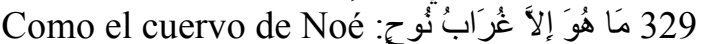

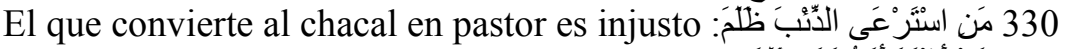

El que actúa como su padre no es injusto 331

332

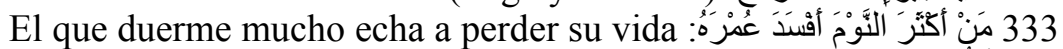

Más dulce que la miel 334

Más pegajoso que una garrapata. 335

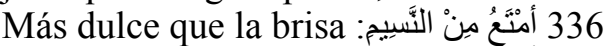

337 أمْْحَح مِنْ رُبَّاح: 338

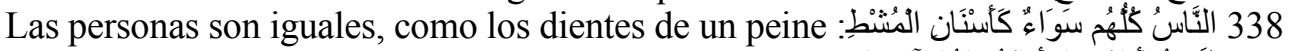

339

340

Destruir es más fácil que construir 341

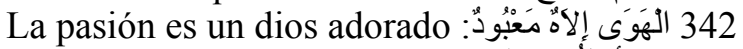

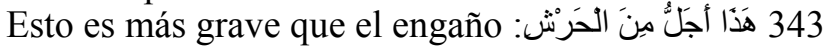

La promesa del noble es una deuda 344

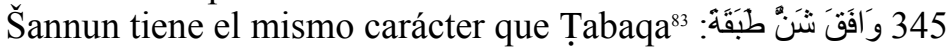

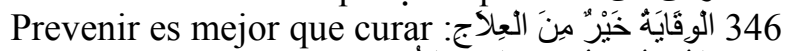

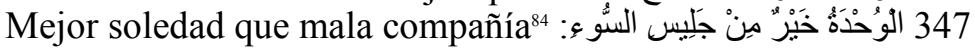

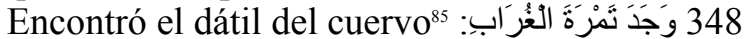

349

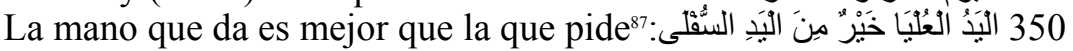

${ }^{81}$ Equivalente a: "El hijo que se parece a su padre acredita de honesta a la madre". Kleiser, pág. 347 , refr. $n^{\circ} 30.642$.

${ }^{82}$ Este proverbio resume la casabiyya, o solidaridad tribal de los árabes preislámicos.

${ }^{83}$ Šannun y Tabaqa son dos personajes de la época preislámica con caracteres parecidos y protagonistas de un cuento tradicional árabe.

${ }^{84}$ Equivale a: "Más vale estar solo que mal acompañado".

${ }^{85}$ Colocado en lo alto de la palmera donde llega el cuervo.

${ }^{86}$ Lit.: "Hoy vino y mañana será otro asunto".

${ }^{87}$ Lit.: "La mano de arriba es mejor que la mano de abajo". 